\title{
Avoiding a senseless endurance test: Hidden disabilities and interviewing in LIS
}

\author{
Keren Dali, Editor-in-Chief
}

Keywords: hidden disabilities; hiring; job interviews; Library \& Information Science; neurodiversity

Publication Type: editorial

Editorial

\section{Instead of an Introduction}

$\mathrm{S}$ everal recent trends on the job market, which have marked an increased recruitment of candidates with autism spectrum disorders to the information technology (IT) sector (e.g., Austin \& Pisano, 2017; Compton, 2017; Deveau, 2018; McGee, 2012; National Symposium, n.d.; "Neurodiverse Individuals," 2018; Simpson, 2017; Somashekhar, 2015; Templeton, 2016), have fueled a wider conversation about the interviewing process for people with disabilities. Candidates with different types of disabilities face an array of challenges and tough decisions at every stage of the application and interviewing process; however, these challenges somewhat vary depending on the type of disability, the employer's hiring procedures and attitudes, and the candidate's choices related to managing the interview process. For example, application and interview experiences may be different for the candidates with observable disabilities, neurodiverse candidates, and for candidates with hidden or less apparent disabilities. An argument can be made that IT is part of the "information science" job market and, to some extent, this is correct; however, positive changes and experiences in the IT recruitment and retention of diverse candidates cannot be automatically generalized to libraries, archives, museums (LAM), and academia. The essential difference between most LAM/academic departments and IT jobs is that the former are people-oriented and communication-intensive while the latter are largely object-, technology-, and task-focused.

\section{A Field for the Socially "Fittest"?}

Flexibility, adaptability to change, the skill of multitasking and managing uncertainty, and interpersonal communication have become a mainstay of job requirements and some of the most sought-after qualities for library and information science (LIS) positions, both professional and academic.

I used to love the concept of flexibility and adaptability as professional competencies. Had valorized it, really. Up to the point whereby one student in my class-who was open about their 
disability-commented that their condition was all about thinking and behavioral patterns, rituals, and familiarity, which gave them the needed structure to function day-to-day and to be creative and successful at school and at work. After my emphatic pitch about the qualities we expect today of the information professional, they asked me point-blank: "Does it mean I do not fit in?" This made me pause. Does it? Has our race for recruiting and retaining flexible, adaptable, and personable communicators paradoxically encouraged narrow-mindedness, inflexibility, and exclusion in our employment practices, defying the value of diversity and keeping out those who are not "typical" for reasons of neurodiversity and/or disability? Is it one of those unfortunate roads paved with good intentions?

As a domain, LAM and academia have become a site of fluid boundaries, high pace, accelerated speed, unpredictability, and constant change, with the ensuing "demand for multi-tasking, as well as an increased emphasis on flexibility and sociability as prerequisites for employability" (McGee, 2012, p. 12). This "temporal environment of accelerated work schedules," as Susan Wendall (2013) argues, "has created a whole new sector of the debilitated, if not fully disabled: those with deficits of attention, flexibility, or sociability" (McGee, 2012, p. 13). However, while the IT sector of our field seems to have found a way to attract the tremendous and unique talent of the diverse workforce, including neurodiverse individuals, LAM and academia, with their hearteningly human-centered orientation, dishearteningly does not find a place for the meaningful engagement of disabled employees.

Most importantly, we do not hold many consequential or actionable discussions of these issues in our field. The growing body of autism-related research in LIS is dedicated to engaging or serving users on the autism spectrum, mostly children, and their families. Very few publications turn their attention to employees on the spectrum, with such notable exceptions as Lund (2018) and Miner \& Morris (2009). On some level, we are probably anxious about a possible conclusion: in the fluid, rapidly changing, people-focused, and communication-driven environment, we cannot find a place for those who cannot adapt fast enough, express boundless flexibility, and become people persons. Candidates with disabilities should be qualified to do a job (with reasonable modifications); however, if they cannot perform "essential functions" of the job at hand, disability disqualifies them from certain positions. Is it the case here? Have LAM and academia become a field for employing the socially, psychologically, and physically "fittest"?

I'll try to address (rather than find answers to) this question within the limited context of job interviewing and with a full realization of the geo-social limitations of my argument.

\section{What Are Neurodiversity and Hidden Disabilities?}

The concept of neurodiversity has become more prominent in recent professional and scholarly literature, as well as media publications.

Neurodiversity is a concept where neurological differences are to be recognized and respected as any other human variation. These differences can include those [living] with Dyspraxia, Dyslexia, Attention Deficit Hyperactivity Disorder, Dyscalculia, Autistic Spectrum, Tourette Syndrome, and others. (National Symposium, n.d., para. 1).

As the above definition highlights, neurodiversity is not associated exclusively with autism spectrum but includes other conditions as well; however, "persons whom the medical, psychiatric, and educational domains would categorize as autistic or 'on the autism spectrum'”

The International Journal of Information, Diversity, \& Inclusion, 3(1), 2019

ISSN 2574-3430, https://jps.library.utoronto.ca/index.php/ijidi 
have been the "most vocal advocates for neurodiversity," with discussions extending "from the disabilities rights movement into the realm of cognitive, affective, and perceptual difference." (McGee, 2012, p.12)

In turn, hidden disability is known to us under different names. One that has been prevalent for a long time (but has recently caused some concerns and objections by certain individuals) is invisible disability; while many find this term acceptable, others prefer to use hidden, latent, or less apparent disability to designate a disability that may not be easily observable but that "limits a person's movements, senses, or activities" nonetheless (Invisibledisabilities.org, n.d., para. 1). Hidden disability may include but not be limited to psychiatric conditions, developmental and learning disabilities, neurodiversity, and physical disabilities that have symptoms felt by the disabled individual but not immediately obvious to others, as it may happen in the cases of arthritis, lupus, multiple sclerosis, and other auto-immune disorders, or in the cases of visual, hearing, and mobility impairments if individuals do not use visual, hearing, or mobility aids. Challenges that people experience are, therefore, psychological, neurological, and physical, including such symptoms as "extreme fatigue, dizziness, pain, and cognitive impairments" that can range from bothersome and inconvenient to downright debilitating (DisabledWorld, n.d., para. 2). For a third party who cannot observe these symptoms directly and who has no relatable personal experience (and cannot draw an empathetic comparison), the nature of hidden disability can be bewildering and hard to understand. As a result, people with hidden disabilities may be perceived as "faking or imagining" their conditions (DisabledWorld, n.d., para. 3).

This dubious disability status brings about the situation whereby "disabled people with hidden disabilities ... [have] to battle unique barriers, from being judged as workshy, because bosses and colleagues do not believe they're disabled, to the dilemma of whether to disclose their disability at all" (Ryan, 2017, para. 5). As one individual with hypermobility syndrome, a connective tissue disorder, pointed out, "there's a total lack of understanding in the workplace, as in the wider world, of what a hidden disability is, whether it is real or not, whether it could exist at all"; "to most people, a disability still means being in a wheelchair." (Ryan, 2017, para. 4) For employees with "a hidden disability," the work situation may feel as though their "job is in jeopardy all the time" (Ryan, 2017, para. 6).

Those who are still on the job market are faced with a tough decision: to disclose their disability upfront (and hope for a more adequate interviewing process and a more informed and positively oriented interviewers) or not to disclose (and avoid unspoken doubts, prejudices, and an unverbalized stigma by interviewers, but fight an uphill battle through various interview stages) (see also, Bowman \& Jaeger, 2007, p. 227; Lyons et al., 2018). Frequently, candidates with hidden disabilities who have to make this choice do not trust their (potential) employers to respond favorably if they learn of the candidate's disability (Ryan, 2017) and choose not to disclose.

At the end of the day, though, the effective handling of disability during interviews is not a sole (or primary) responsibility of a disabled individual. The primary responsibility should fall on the shoulders of employers and organizations. Ultimately, it comes down to the need for "raising awareness that hidden disabilities even exist" (Ryan, 2017, para. 17) and for the subsequent "cultural change" "to create a healthy and productive workplace" "for everyone, not 'special treatment'" for disabled people (Ryan, 2017, para. 15). Absent these changes, scores of talented, capable, and creative people with hidden disabilities will be fully or partially excluded from productive participation in the workforce. As one latently disabled

The International Journal of Information, Diversity, \& Inclusion, 3(1), 2019

ISSN 2574-3430, https://jps.library.utoronto.ca/index.php/ijidi 
person noted: "If there's a glass ceiling for women, there's a much thicker one for people with hidden disabilities" (Ryan, 2017, para. 19).

It is not clear what percentage of faculty members and practitioners at LAM and academia have hidden disabilities. Statistical data about the extent of disability in LIS workplaces is incomplete and fairly unreliable, especially with regard to hidden disabilities, due to high rates of non-disclosure and difficulty collecting these kinds of statistics (e.g., Shigaki et al., 2012).

\section{The Focus of This Editorial}

This editorial focuses primarily on individuals with hidden disabilities, a category that encompasses a certain percentage of neurodiverse individuals as well. However, neurodiversity is not always hidden. For example, some characteristic communication patterns of people with autism, dyspraxia, or ADHD may certainly be observable (e.g., difficulty keeping eye contact; the literal interpretation of questions; the need for immediate attention to distractions; a short attention span; a lack of certain motor skills; restlessness; rituals, etc.). The discussion of these kinds of neurodiverse behaviors requires a special treatment and, as such, they are out of the scope of this editorial. This editorial accounts only for those neurodiverse individuals whose atypical needs affect their job search process but are largely hidden from a third party. Also, while the hiring process is much broader and more involved, the focus of this editorial is on inperson interviewing. Broader questions of the training, retention, and engagement of employees with hidden disabilities definitely warrant additional, follow-up publications.

\section{An Interviewing Process for the Physically and Psychologically "Fittest"?}

Over a decade ago, Bowman \& Jaeger (2007) drew attention to the academic interviewing process and its inadequacy and challenge for candidates with disabilities. Writing in the context of the U.S., they noted that even disability legislation had not had "a sizeable impact on disability discrimination in hiring" (p. 226). The interview process, they noted, could easily turn into one of the most trying experiences.

Academic interviews on campus for short-listed candidates (which happen after a screening round of short phone or online interviews) usually have a packed and intensive schedule spread over one or two days; this schedule usually consists of a formal presentation, a panel interview, a meeting with the Dean/Chair, and multiple short interviews/meetings with individual faculty members and administrators; in some cases, there are also group meetings with students (often divided into undergraduate, Master, and Ph.D. groups) and a ritual lunch and/or dinner with members of the search committee (and other community members). The hiring process for academic librarians is often similar, albeit shorter and less intensive, with fewer meetings included. Hiring in other types of libraries and information organizations varies from place to place; however, it is highly unlikely that the process will be limited to one or two meetings or to just a panel interview.

Bowman \& Jaeger (2007), who discussed candidates with both observable and hidden disabilities, mention interviewing logistics, potential awkwardness in interpersonal interactions, scheduling, travel arrangements, and getting around the campus as some of the challenges experienced by candidates with disabilities. They also caution that if the candidates' area of research is disability-related, while their own disability is hidden, candidates should also be prepared to handle questions about their personal path to disability studies and to make a separation between their personal situations and scholarly pursuits.

The International Journal of Information, Diversity, \& Inclusion, 3(1), 2019

ISSN 2574-3430, https://jps.library.utoronto.ca/index.php/ijidi 
A more foundational question though is the very nature of the interviewing process, its usefulness, intent, and fairness. It is clear that the multiple formats (one-on-one meetings, panel interviews, group meetings, a combination of formal and informal conversations, and research presentations) are chosen to increase the objectivity of interviewing and to get as holistic an assessment of the candidate as possible. However, there comes a point whereby this process becomes excessive and hypertrophied, difficult for any candidate, and especially disadvantageous for candidates with disabilities. I personally remember one interview whereby I had 12 events in a single day, which included lunch and dinner (which can be as anxietyinducing as any other meeting), a formal presentation, eight one-on-one meetings, and a panel interview. The next half a day featured five meetings. (To be sure, there are many reasonably scheduled interviews; however, there are plenty of unreasonable ones).

To any sensible person, this schedule should seem counterproductive. The process will surely drain anxiety-ridden candidates to the blurry-eyes-shaky-legs state; by the end of the whole production, they will remember nothing but a kaleidoscope of faces, matching names to these faces only accidentally and sporadically. They will likely lose much of their focus and concentration at a half-a-way mark and go through the rest of the meetings on autopilot, muttering something rehearsed and formulaic and, regrettably, not enjoying many conversations, even if they happen to meet with distinguished people in the field. If lunches and dinners are replete with questions-related to the candidate's work or even social life and personal hobbies-they will be just as trying; it is doubtful that the candidate will be able to eat, replenish their energy, and catch a break. Albeit on a smaller scale, hiring in other sectors of LAM may suffer from the same afflictions.

But here is the question: what does this process accomplish, exactly, aside from sending candidates off exhausted and tripling their anxiety? These schedules and agendas do not resemble a typical academic or library work environment. Even if we have multiple meetings in a day (which we do), most meetings are work-related and routine and, usually, do not require constant self-promotion and self-presentation; they do not involve career-changing assessments and judgements; not always do we find ourselves at a power disadvantage or in a dependent position, as it happens during interviewing. Even if we often perform under pressure at work, it is a different kind of pressure. And even if we go through crazy days at conferences and other venues sometimes, we are rarely in a situation of being constantly evaluated, as we are at job interviews.

So, really, what kind of a senseless endurance test do excessively heavy interview schedules put candidates through? What do they detect? What do they show? Are they designed to test the limits of how quickly people get worn out and drop the ball? Do we, wittingly or unwittingly, establish a process that facilitates the (un)natural selection of "the fittest" candidates for academic and library positions: those with greatest physical endurance; with most psychological preparedness; with off-the-charts sociability? Do we allow these qualitiesnot listed in any job description-to become de facto selection criteria?

Now, imagine a candidate with hidden disabilities. Due to the nature of neurological, psychiatric, and developmental conditions, people with hidden disabilities may require more breaks, periods of rest, a slower pace, fewer stimuli or engagements during the day, and so on. They need it to stay sharp, intellectually productive, well-oriented, calm, and focused, and to cope with physical symptoms of weakness, dizziness, fatigue, digestive issues, and so on. So, imagine, that such a candidate sees 12 daily engagements on their schedule and realizes that they cannot withstand this kind of pressure-then what? 
They may decide to disclose their disability to the potential employer and ask for a gentler, less loaded schedule that will work with their condition. You can also imagine the dynamics from this point forward. This candidate will get fewer meetings than other campus visitors; there will be questions in this regard from faculty members who wanted to but could not meet the candidate; there will likely be comments about the ability of the candidate to be productive and "fit in" the "busy academic department" (although, as shown just above, unreasonable interview schedules have nothing to do with "busy academic life"); and so on and so forth. As a result, even before the visit materializes, there are less favorable and less receptive conditions for the candidate with hidden disabilities. Plus, if the exact nature of the hidden disability is not disclosed along with a request for accommodations, there will likely be speculations about "what this person has."

However, reasonable and thoughtful scheduling and a few simple adjustments to the interview process could easily obviate the need for many candidates with hidden disabilities to disclose their condition, should this be their preferred choice. Imperative is an interviewing process that will allow them to cope with their daily symptoms and, if needed, maintain "a therapy or medication regimen" (Bowman \& Jaeger, 2007, p. 229).

\section{What Can Be Done?}

What I am advocating below are not disability "accommodations" (a legal, recognizable term that I have come to deeply resent; see Dali, 2018). What I am advocating for is a more inclusive process for every candidate, which accounts for a broad range of human conditions and limitations and, by extension, can greatly benefit candidates with hidden disabilities.

Below, I list certain statements to consider and possible actions or solutions that can be implemented to address them.

- Even people who do not use mobility aids may have mobility problems. For example, people with auto-immune and neurological conditions, or people with muscle weakness, resulting from treatment, medications, or injury, may have a hard time walking fast or climbing up and down the stairs.

Consider heading for an elevator or an escalator as a default option; do not put people in the position to tell you that they prefer an elevator over stairs. If they indeed prefer stairs-they will likely let you know. Slow down as you take the candidate on a campus tour or guide them from interview to interview; do not put people in the position to ask you to slow down. Make sure that candidates do not have an unnecessary weight on them-think of a place to securely park their bags for the day of the interview; if this is not possible, offer assistance in carrying their belongings-even people without disabilities may not decline! It is a courteous and thoughtful gesture that will go a long way.

- Many neurological, psychiatric, or developmental conditions, and/or accompanying treatments, result in dizziness, difficulty in spatial orientation, fatigue, reduced concentration, and hypersensitivity to multiple stimuli. This means that people with hidden disabilities may tire more quickly and begin to function less effectively sooner than candidates without disabilities.

Unload your interviewing schedule to help candidates focus better on the next upcoming conversation and take a breather before the next meeting. Four to five events (including a 
panel interview and a formal presentation) may be optimal. However, if in doubt, consult with HR specialists and organizational psychologists on campus about the number of events that candidates can handle without getting overly tired and still maintaining intellectual acuity, motivation, concentration, and a good mood. To ensure that as many interested faculty members as possible have a chance to meet the candidate, invite faculty members to meet the candidate as a group. Then, individual meetings will be reserved for the Dean or other toplevel administrators. Consider thematic informal meetings of which the candidate will be aware in advance: meetings about research; meetings about teaching; meetings about service; meetings to get familiar with PhD students and Master students; and so on. This will make meetings more productive and candidates more focused, also alleviating much anxiety caused by the unknown and the uncertain.

- Even if it is not always obvious, standing during formal presentations and speaking up can put undue stress and strain on people with hidden disabilities, causing unnecessary exertion that will impair the quality of their presentations and engagement with the audience.

Make sitting during formal presentations a norm, not an exception or an accommodation. Prepare your room in such a way that the candidate can comfortably choose to stand or to sit through the talk, without having to make excuses and special requests to sit down. In many cases, this does not require much effort or complex technological adjustments. Make sure that there is some sort of a voice amplifier in the room, be it a microphone or loudspeakers. There are few things more aggravating than asking someone to speak up when they cannot and putting them in the position to apologize and make excuses when their sole focus should be on delivering a quality talk. Do not assume that "acoustics are good" and do not go by your personal "I usually have no problem being heard in this room" mantra; this will only make the candidate feel more inadequate.

- Good diet is essential to maintaining a sense of daily well-being and managing symptoms in many people with hidden disabilities. People with hidden disabilities may include those with diabetes and hypoglycemia; those taking medications requiring meals; those who need to eat frequently in small portions; and people with dietary restrictions. Many people with neurological conditions may have digestive difficulties; these are very touchy issues that most are unwilling to disclose. Meal times during interviewing may become the worst nightmare. I have heard endless stories about candidates with disabilities taking diet pills to suppress the appetite on the day of interviewing or taking bathroom breaks to quickly consume Ensure, energy bars, or energy drinks in private.

Remember that digestive issues are not only about dietary restrictions, food allergies, and sensitivities. Make sure that candidates do not go for hours without a drink or nourishment of some sort. Resist the temptation to find out more about the candidate during lunch or dinnerunless they initiate the conversation. Let people eat in peace and allow them to use the meal time as a downtime in their busy day. Do not hold it against them if they talk very little and focus on food instead. Dinners are usually more relaxed, but let candidates take the lead on how the dinner goes; do not bombard them with questions. Some people are really exhausted and quiet at the end of the day, especially if fatigue is one of the main symptoms they battle daily. Do not interpret this behavior as insufficiently sociable, unpleasant, too shy, or too smug. This is usually not the case. 


\section{Points to Ponder}

None of the above modifications require extra money, much effort, or special investment. All they require is awareness, sensitivity, and consideration. As such, they are not difficult to make. However, these simple, thoughtful arrangements, often amounting to no more than common courtesy, kindness, and hospitality, may go a long way in providing a more adequate interviewing environment for people with hidden disabilities and helping many of them go through the interview process without disclosing their conditions, if this is the choice they decide to make.

These suggestions are as applicable to academic interviewing as to interviewing for other LAM positions, and they are easier and faster to implement than any policy change. Even absent formal regulations and guidelines, the proposed adjustments can go a long way in fostering a more inclusive interviewing process that will benefit candidates with disabilities and other candidates as well.

The major challenge here is to rethink what we consider normal and acceptable. It is interesting to observe how certain disabling conditions, which become more and more prevalent and shared by a larger number of people, are no longer perceived as disabilities carrying stigma. For example, back pain and back issues, which can potentially become debilitating and disabling, are now common to so many people with desk jobs that they are almost considered normal. Yet, it is highly doubtful that anyone would consider a request for an expensive ergonomic chair at the workplace as a disability-related accommodation. The same can be said about food allergies which, once again, can be not only debilitating but also life-threatening, bringing a great deal of lifestyle adjustments into the daily schedules of the affected people. Nonetheless, it is considered normal to disclose food allergies at the workplace and at different professional and scholarly venues, and this is a kind of health concern that everyone-from event organizers to caterers-is prepared to accommodate from the get-go. However, if we thought about it rationally, accounting for food allergies usually requires a special effort and results in added expenses; yet, it does not carry the same stigma as would a request to ensure that a job candidate could sit during their formal presentation or that going to lunch does not entail climbing stairs. I doubt that anyone would contemplate not hiring a candidate because of back issues or food allergies.

That is to say, once a disabling condition or a disability becomes more common, our collective narrative easily normalizes it and moves it from the category of stigmatized disability requiring a dreaded "accommodation" to the category of "normal." We would do well to pause and ponder this point.

Another point to ponder is how much is done by faculty and LIS professionals with disabilities, currently employed in LAM and academia, to change the situation and to ensure a more inclusive and receptive interviewing environment and procedures. Although employment rates for people with disabilities are nowhere near acceptable levels, as multiple sources confirm, there are more people with disabilities employed in LAM and academic departments than before. Once these individuals achieve tenure or seniority and have a chance to make a difference, do they use their privilege and take the opportunity not only to advocate rhetorically but to actually implement desired changes?

It is really hard to imagine an LIS department or a library that would not have any faculty members or staff with some type of disability, be it lifelong or acquired. And yet, not all the 
departments have truly sensitive, receptive, and inclusive hiring procedures and protocols. Why is that? What happens to people's desire to change the world once their disadvantage turns into privilege? Or do they still not feel powerful and influential enough to make a difference? Or are organizational structures so unwieldy and exclusive mindsets so engrained that no matter how much you fight them, the result is negligible?

I refuse to believe that people with disabilities stop caring about the big picture and others once they themselves get a job or job security. However, I find it equally hard to believe that the large cumulative amount of life experience, wisdom, individual insight, in-depth awareness, common sense, practical know-how, and-often-personal suffering possessed by employees with disabilities fails to make a difference in workplaces. The sad truth, however, is that, in terms of inclusive interviewing, we are in the same place where we were when Bowman and Jaeger (2007) wrote their chapter over a decade ago. Another stop sign for pause and reflection.

\section{Geo-Social Limitations and an Invitation to Dialogue}

This editorial reflects on the situation in North America and may be relevant to LAM and academia in other countries and regions where working environments resemble those in North America. However, we have very little knowledge about the hiring of and interview processes for people with disabilities in LIS in other parts of the world. Therefore, we would like to hear from our international readers and welcome letters to the editorial team with your experiences, insights, and reflections from your home countries. Excitingly, in October 2019, IJIDI is planning a special issue on "Engaging Disability," guest-edited by Dr. Kim M. Thompson from the University of South Carolina. Interesting and insightful contributions from our readers in response to this editorial may be published in the special section of the October issue.

\section{The Grand Tour of the Current Issue}

Disability is not part of the current January 2019 issue of IJIDI, and that is why I felt that writing an editorial addressing disability would be complementary to a stellar line-up of diverse and innovative articles that we bring today to the reader's attention.

We open with the article by Andrew B. Wertheimer and Noriko Asato that draws us into the rarely seen world of Japanese-language print culture and bookstores in prewar Honolulu. Based on archival sources and published reports on library history, the article delves into the fascinating phenomenon of immigrant print cultures flourishing in the conditions of cultural exclusion and disregard, which characterized the public library approach to the reading aspirations of Japanese Americans of the time.

This article is followed by the empirically grounded and reflective piece by Nadia Caidi that focuses on pilgrimage as an information context and brings to the fore the valuable insights resulting from the merger of scholarships on information and religion. It examines the Hajj pilgrimage in Mecca (Saudi Arabia) as a case in point and uses established theories of information behavior and meaning making in order to explicate information practices of pilgrims as manifestations of a "lived religion."

From everyday information practices and historical library issues, the article by Laila Brown brings us back to LIS departments and learning environments. This empirical study looks at the transformational experiences of LIS students in two book clubs, whose agenda was guided by 
the combined principles of feminist and diversity ethics. It explores how this combined ethic informed students' perceptions of LIS and contemplates its future potential contribution to the careers and professional development of budding LIS practitioners.

An entirely different reflection on diversity issues and young people comes from the article by Jeanie Austin, which gives voice to the LGBTQ (Lesbian, Gay, Bisexual, Transgender, and Queer) and gender non-conforming youth of color. Turning our attention to the oppressive forces that come not only from governmental and public institutions but also from the publishing industry, it sheds light on the effects of oppression on the young people's lives. Using a case study from a public library in California, the article advocates for greater diversity and inclusion in library collection building practices in the context of critical race theory.

The article section closes with the critical and insightful viewpoint piece by Rachel Wexelbaum, which builds on the available findings on the reading habits and preferences of LGBTIQ+ youth. The article discusses their information seeking behavior and challenges they face in locating desired reading materials, in print and on social media; it also provides recommendations to librarians on making collections more relevant to LGBTIQ+ youth.

Our special section with "Reports from the Field" includes the article by Rae-Anne Montague and Joseph A. Coyle that addresses a patchwork of services for incarcerated youth. Drawing on the experiences of several dedicated individuals and groups, the authors critically consider the topics of awareness building, resource sharing, and meeting the information needs of incarcerated youth.

The issue also features a new collection of book reviews edited by Norda A. Bell. The following titles are reviewed: Algorithms of Oppression: How Search Engines Reinforce Racism by Safiya Umoja Noble (reviewed by Kelly M. Hoffman); Pushing the Margins: Women of Color and Intersectionality in LIS, edited by Rose L. Chou and Annie Pho (reviewed by Alyssa V. Loera); Self-Determined Stories: The Indigenous Reinvention of Young Adult Literature by Mandy SuhrSytsma (reviewed by Treasa Bane); and Academic Libraries for Commuter Students: Researchbased Strategies, edited by Mariana Regalado and Maura A. Smale (reviewed by Norda A. Bell).

Finally, a few words about our cover art choice for the January issue. It features a summer garden from Northern Canada, rather than more expected wintery pictures. IJIDI is an international journal, and this is the best original image we had to remind our readers that while it is cold and frosty in the West, January has different associations for people living around the world. I would also like to take this opportunity to note that IJIDI always welcomes original art contributions for our future covers, and we invite our readers to send us their original images conveying concrete or abstract representations of diversity. If images include people, consent from all depicted individuals should be secured before the image is sent to us.

Enjoy the new issue of IJIDI and keep in touch!

\section{References}

Austin, R. D. \& Pisano, G. P. (2017). Neurodiversity as a competitive advantage. The Harvard Business Review. Retrieved from https://hbr.org/2017/05/neurodiversity-as-acompetitive-advantage

Bowman, C. \& Jaeger, P. (2007). Academic interviews and persons with disabilities. In Vance, 
M.L. (Ed.), Disabled faculty and staff in a disabling society: Multiple identities in higher education (pp. 225-234). Huntsville, NC: AHEAD.

Compton, J. (2017, August 24). How is neurodiversity changing how companies recruit? Retrieved from https://resources.workpop.com/blog/neurodiversity-recruiting .

Dali, K. (2018). The right to be included: Ensuring the inclusive learning and work environment for people with disabilities in academia. Information \& Learning Science, 119(9/10), 486-513.

Deveau, D. (2018, March 27). Five ways to welcome those on the autism spectrum into the workplace. The Financial Post. Retrieved from https: / / business.financialpost.com/executive/five-ways-to-welcome-those-on-theautism-spectrum-into-the-workplace

Disabled World. (n.d.). Invisible disabilities: List \& information. Retrieved from https://www.umass.edu/studentlife/sites/default/files/documents/pdf/Invisible\%20Di sabilities\%20List $\% 20 \% 26 \% 20$ Information.pdf

Invisibledisabilities.org. (n.d.). How do you define invisible disability? Retrieved from https: / /invisibledisabilities.org/what-is-an-invisible-disability/

Lund, B. D. (2018). Redefining opportunity for the library employee with autism: A model of positive behavioral support for library management. Journal of Library Administration, 58(5), 434-448.

Lyons, B. J. et al. (2018). To say or not to say: Different strategies of acknowledging a visible disability. Journal of Management, 44(5), 1980-2007.

McGee, M. (2012). Neurodiversity. Contexts, 11(3), 12-13.

Miner, M. \& Morris, A. (2009). Working within the spectrum: Employees with Asperger Syndrome in our library. ILA Reporter, 27(4), 16-20.

National Symposium on Neurodiversity at Syracuse University. (n.d.). What is neurodiversity? Retrieved from https://neurodiversitysymposium.wordpress.com/what-isneurodiversity/

Neurodiverse individuals considered ideal for cybersecurity jobs. (2018). Disability Horizons. Retrieved from http://disabilityhorizons.com/2018/07/neurodiverse-individualsconsidered-ideal-for-cybersecurity-jobs/

Ryan, F. (2017, February 21). Hidden disabilities at work: “Every day I'm fatigued and in pain.” The Guardian. Retrieved from https: / / www.theguardian.com/careers/2017/feb/21/hidden-disabilities-at-workeveryday-im-fatigued-and-in-pain

Shigaki, C.L., Anderson, K.M., Howald, C.L., Henson, L. and Gregg, B.E. (2012). Disability on campus: A perspective from faculty and staff. Work, 42(4), 559-571.

Simpson, C. (2017, December 5). Neurodiverse practices; How to hire people with autism. 
Focus Professional Services. Retrieved from https: / /focusps.ca/neurodiverse-practiceshire-people-autism/

Somashekhar, S. (2015, July 20). How autistic adults banded together to start a movement. The Washington Post. Retrieved from https://www.washingtonpost.com/politics/the-nextcivil-rights-movement-accepting-adults-with-autism/2015/07/20/e7c6743e-f338-11e4bcc4-e8141e5eb0c9_story.html?noredirect=on\&utm_term=.d3f31bf9dc9b

Templeton, S. (2016, November 3). In neurodiversity there is beauty, strength, and skills you don't have. ITSP Magazine. Retrieved from https: / / www.itspmagazine.com/from-thenewsroom/in-neurodiversity-there-is-beauty-strength-and-skills-you-dont-have

Wendall, S. (2013). The rejected body: Feminist philosophical reflections on disability. Hoboken, NJ: Taylor \& Francis.

Dr. Keren Dali (keren.dali@alumni.utoronto.ca) is Editor-in-Chief of IJIDI. Her research interests are in diversity and inclusion at the workplace; relationships between LIS and Social Work; disabilities; LIS education with the focus on creativity, accreditation, and humanistic pedagogies; and reading behaviors. With a background in Social Work and LIS, Dr. Dali holds the inaugural Outstanding Instructor Award from the Faculty of Information, University of Toronto; the inaugural ALISE/Connie Van Fleet Award for Research Excellence in Public Library Services to Adults; the Outstanding Reviewer distinction and the Outstanding and Highly Commended Paper distinctions from the Emerald Literati Network Awards for Excellence. Her work has been funded by the grants from the Social Sciences \& Humanities Research Council of Canada (SSHRC) and the American Library Association, among others. She's active in ASIS\&T, ALISE, and IFLA, chairing committees for both ASIS\&T and ALISE. She is a winner (with Nadia Caidi) of the ALA David Cohen/EMIERT Multicultural Award 2018 for the co-authored article "Diversity by Design" published in The Library Quarterly. 